\title{
The Relationship Between Dyslipidemia and Lupus Nephritis in Systemic Lupus Erythematosus Patients Attending a Saudi Rheumatic Center, Tabuk
}

\section{Hyder Osman Mirghani ${ }^{*}$, Abdullah Abdul Khalig Alyoussef², Osama Salih Mohammed ${ }^{3}$, Palanisamy Amirthalingam²}

1. Department of Medicine, Faculty of Medicine, University of Tabuk, Tabuk, Kingdom of Saudi Arabia

2. Department of Clinical Pharmacy, Faculty of Pharmacy, University of Tabuk, Tabuk, Kingdom of Saudi Arabia

3. King Fahd Specialist Hospital, Al Qadsiyyah, Tabuk, Saudi Arabia

Corresponding Author: s.hyder63@hotmail.com.

Received 09 December 2019 Accepted 05 March 2020 Published 31 March 2020

Production and Hosting by Knowledge E

@Hyder Osman Mirghani. This article is distributed under the terms of the Creative Commons Attribution License, which permits unrestricted use and redistribution provided that the original author and source are credited.

Editor-in-Chief:

Prof. Mohammad A. M. Ibnouf

\section{Abstract}

Background: There is an increasing awareness of the role of dyslipidemia in lupus nephritis patients, no researchers have studied dyslipidemia in systemic lupus erythematosus (SLE) in Tabuk. In this study, we aimed to investigate the association between dyslipidemia and lupus nephritis in Tabuk, Saudi Arabia.

Methods: This cross-sectional comparative longitudinal hospital-based study was conducted at a rheumatic clinic in the North West Armed Force Hospital (NWAFH) during the period April 2014-June 2015. Seventy-three patients diagnosed with SLE were invited to participate in the study. All participants were required to sign a written informed consent, following which they were interviewed using a structured questionnaire. Data collected include demographic data, clinical characteristics, fasting lipid profile, renal function tests, urine analysis, antinuclear antibody, anti-double-stranded antibodies, complement levels, serum albumin, anticardiolipin, ant bodies, and antiphospholipid antibodies. Lupus nephritis was ascertained by renal biopsy. The research was approved by the ethical committees of both the University of Tabuk and the NWAFH and data were analyzed using the Statistical Package for Social Sciences (SPSS).

Results: Out of 73 patients with SLE, $86.3 \%$ were females with a mean age of $34 \pm 6.4$ years. Lupus nephritis was evident in $26 \%$ of the patients, proteinuria in $44.1 \%$, high total cholesterol in $17.8 \%$, high low-density lipoprotein in $15.1 \%$, high triglycerides in $27.3 \%$, and low high-density lipoproteins in $52.1 \%$. Patients with lupus nephritis had high total cholesterol, high LDL, high TG, and low HDL than those without lupus nephritis $p<0.05$.

Conclusion: Dyslipidemia was more common among patients with SLE nephritis, and an aggressive treatment is recommended to reduce this serious complication. The relatively small size of the study group and the fact that the study was conducted at a single tertiary center are the limitations of this study.

Key words: Dyslipidemia, lupus nephritis, Saudi Arabia 


\section{Introduction}

Systemic lupus erythematosus (SLE) is a chronic autoimmune disease found in women in their childbearing age; nearly one-fifth of the cases occur in the first two decades of a woman's life. The disease runs a remitting-relapsing course with breakout difficult to control. Cardiovascular disease is the most common cause of death among patients that acquire the disease for more than five years [1].

Accelerated atherosclerosis and premature ischemic heart disease are common causes of mortality and morbidity among patients with SLE. Increasing age is a risk factor for coronary heart disease but unlike the general population, young women with SLE are more affected. The potential for cardiovascular disease including myocardial infarction, cerebrovascular and peripheral arterial disease in young women with SLE is approximately double than that in the general population [2, 3].

Several pathophysiological mechanisms mediate coronary heart disease including atherosclerosis, arteritis, thrombosis, spasm, embolization, and abnormal coronary flow [4]. It is strongly suggested by epidemiological studies that in addition to conventional coronary risk factors, there are non-classical risks in SLE patients, in fact, SLE is considered an independent risk factor for atherosclerosis [5, 6].

A recently published research concluded that regardless of food intake and nutritional status, preserved kidney function, low disease activity, and low steroid dose, adolescent females with SLE have proatherogenic lipid biomarkers that may contribute to atherosclerosis risks [7].

In this regard, dyslipidemia was found to be prevalent in SLE patients (55-77\%), especially among those with active disease, heavy proteinuria, and concomitant medications. Furthermore, cardiovascular complications are the leading cause of death among SLE patients with renal failure, and renal impairment was found to be associated with dyslipidemia [8].

No researcher has studied dyslipidemia in SLE patients in Tabuk, Saudi Arabia. Thus, the present study was conducted to investigate the relationship of dyslipidemia among patients with SLE in Tabuk.

\section{Materials and Methods}

This cross-sectional descriptive, longitudinal, hospital-based study was conducted between June 2014 and April 2015 among patients attending the rheumatic outpatients' 
clinic in the North West Armed Force Hospital. Seventy-three patients above the age of 18 years diagnosed with SLE based on the American College of Rheumatology Criteria (ACR) [9] signed a written informed consent form before being interviewed and examined by the researcher (a rheumatologist). A structured questionnaire was used to obtain sociodemographic data and clinical characteristics including lupus nephritis based on renal biopsy findings, myocardial infarction, stroke, infections, hypertension, pre-hypertension, and hypotension. All patients were in remission at the time of lipid measurements as indicated by serological markers. Patients with active disease were excluded from the study as well as those on steroid dose $>10 \mathrm{mg} /$ day, diabetic patients, patients with nephrotic range proteinuria, those with chronic liver disease or active malignancy, patients diagnosed with familial dyslipidemias, active thyroid disorders, and patients on oral contraceptive pills. The following investigations were undertaken: urinalysis for RBCs cast, albumin, and pus cells, full blood count, complement level, erythrocyte sedimentation rate (ESR), high sensitive C-reactive protein (CRP), and antinuclear antibody profile (ANA).

Total cholesterol and triglycerides were measured using a colorimetric enzyme assay (NingBo RuiYuan Biotechnology Co., Ltd., Zhejiang, China). HDL-C and LDL-C were quantified using the GPO-PAP method (Beckman Coulter, Miami, FL, USA). The urease method from BUN Healthcare Diagnostics Newark DE 19714 USA was used for blood urea nitrogen measurement, and serum creatinine was ascertained using CREA Healthcare Diagnostics Newark, DE 19714 USA based on the idea that in the presence of $\mathrm{NaOH}$, pectate reacts with creatinine to form a red chromophore measurable by bichromatic (510e600).

For the purpose of this research, the following definitions were adopted:

- Hypertension: self-reported, on antihypertensive therapy, history of systolic blood pressure $>140 \mathrm{mmHg}$ or diastolic blood pressure $>90 \mathrm{mmHg}$.

- Abnormal lipid profile: total cholesterol $[\mathrm{TC}] \geq 5.18 \mathrm{mmol} / \mathrm{L}$; triglyceride $[\mathrm{TG}]$ $\geq 2.26 \mathrm{mmol} / \mathrm{L}$; high-density lipoprotein cholesterol [HDL-C] $<0.91 \mathrm{mmol} / \mathrm{L}$; lowdensity lipoprotein cholesterol $[\mathrm{LDL}-\mathrm{C}] \geq 3.37 \mathrm{mmol} / \mathrm{L}$, according to the Adult Treatment Panel III criteria [10].

The ethical committee of the University of Tabuk and the local committee approved the research, and the Statistical Package for Social Sciences was used for data analysis. The Chi-square test was used to compare categorical data, and data were presented as a mean \pm SD and percentages unless otherwise specified with a $p<0.05$ considered as significant. 


\section{Results}

Female dominance (86.3\%) was obvious in the 73 studied patients, their age ranged from 20 to 50 years with a mean age of $34 \pm 6.4$ years. Lupus nephritis was found in $26 \%$ of the patients, stroke was evident in $8.2 \%$, while myocardial infarction was concluded in 1.4\% of the SLE patients. Other clinical characteristics are shown in Table 1. Table 2 illustrates the laboratory investigations among SLE patients in which high total cholesterol was found in $17.8 \%$, high LDL in $15.1 \%$, high triglycerides in $27.3 \%$, while low HDL was observed in $52.1 \%$. In the present study, proteinuria was found in $44.1 \%$ of the SLE patients, RBCS cast was found in $27.5 \%$, raised urea and creatinine were observed in $7.9 \%$, and low serum albumin in 71.45. Regarding immunological screening, ANA was positive in $98.6 \%$, antidouble stranded antibody was positive in $100 \%$, antismith antibodies were positive in $26 \%$, anticardiolipin was positive in $13.7 \%$, antiphospholipid was positive in $3.9 \%$, while antiribonucleoprotein was positive in $20.5 \%$.

TABLE 1: Clinical Characteristics of Systemic Lupus Erythematosus Patients.

\begin{tabular}{|l|}
\hline Character \\
\hline Lupus nephritis \\
\hline Stroke \\
\hline Myocardial infarction \\
\hline Pulmonary embolism \\
\hline Neuropsychiatric manifestations \\
\hline Hypertension \\
\hline Prehypertension \\
\hline Hypotension \\
\hline Infections \\
\hline
\end{tabular}

\begin{tabular}{|c|}
\hline No. $(\%)$ \\
\hline $19(26 \%)$ \\
\hline $6(8.2 \%)$ \\
$1(1.4 \%)$ \\
\hline $4(5.5 \%)$ \\
\hline $26(35.6 \%)$ \\
$11(15.1 \%)$ \\
$19(26 \%)$ \\
$25(34.2 \%)$ \\
$10(13.7 \%)$ \\
\hline
\end{tabular}

TABLE 2: Laboratory Investigations of SLE Patients.

\section{Investigation}

High total cholesterol

High LDL

High TG

Low HDL

Proteinuria

Red blood cells cast

Raised urea \& creatinine

Low albumin

Antinuclear antibodies positive

Antidoubles stranded antibodies

Antismith antibodies positive

Anticardiolipin positive

Antiphospholipid positive

Antiribonucleoprotein positive

\begin{tabular}{|c|}
\hline No. $(\%)$ \\
\hline $13(17.8 \%)$ \\
\hline $11(15.1 \%)$ \\
\hline $20(27.3 \%)$ \\
\hline $38(52.1 \%)$ \\
\hline $30(44.1 \%)$ \\
\hline $19(27.5 \%)$ \\
\hline $5(7.9 \%)$ \\
\hline $45(71.4 \%)$ \\
\hline $72(98.6 \%)$ \\
\hline $13(100 \%)$ \\
$19(26 \%)$ \\
\hline $10(13.7 \%)$ \\
\hline $3(3.9 \%)$ \\
\hline $15(20.5 \%)$ \\
\hline
\end{tabular}


In the current study, the total cholesterol was higher among patients with SLE nephropathy $5.40 \pm 1.46 \mathrm{mmol} / \mathrm{l}$ vs $4.36 \pm 0.82$ with a significant statistical difference, $p$ value was $0.003, \mathrm{LDL}$ was $3.13 \pm 0.82 \mathrm{mmol} / \mathrm{l}$ vs $2.66 \pm 0.53$ in patients with nephropathy and those without nephropathy, respectively, with significant statistical difference, $p=0.028$; triglycerides were higher in lupus nephritis $2.31 \pm 1.54 \mathrm{mmol} / \mathrm{l}$ vs $1.28 \pm 0.72$ with a $p=0.003$, no significant statistical difference was evident regarding high-density lipoproteins levels (see Table 3).

TABLE 3: The Relationship Between Dyslipidemia and Lupus Nephritis.

\begin{tabular}{|l|c|c|c|}
\hline & Lupus nephritis & Others & $p$ value \\
\hline $\begin{array}{l}\text { Total cholesterol } \\
\text { (>5.2 } \mathbf{~ m m o l )}\end{array}$ & $5.40+1.46$ & $4.36+0.82$ & 0.0036 \\
\hline $\begin{array}{l}\text { Triglycerides } \\
\text { (>1.7 } \mathbf{~ m m o l )}\end{array}$ & $2.31+1.54$ & $1.28+0.72$ & 0.0033 \\
\hline $\begin{array}{l}\text { LDL } \\
\text { (>3.4) }\end{array}$ & $3.13+0.82$ & $2.66+0.53$ & 0.0285 \\
\hline $\begin{array}{l}\text { HDL } \\
\text { (Male }<\mathbf{1 ~} \mathbf{m m o l} \text {; } \\
\text { Female }<1.5 ~ \mathbf{~ m o l )}\end{array}$ & $1.11+0.32$ & $1.18+0.23$ & 0.3901 \\
\hline
\end{tabular}

In the current data, the total cholesterol was higher among patients with proteinuria $5.20 \pm 1.31 \mathrm{mmol} /$ liter vs $4.28 \pm 0.88$ with a significant statistical difference of $p$ value 0.007 , LDL was higher among patients with proteinuria $3.06 \pm 0.73$ vs $2.60 \pm 0.52$ with a significant statistical difference of $p$ value 0.024 . Table 4 depicts the relationship between lipid profile and proteinuria among SLE patients.

TABLE 4: The Relationship of Dyslipidemia and Proteinuria.

\begin{tabular}{|c|c|c|c|}
\hline & Proteinuria & Others & $p$ value \\
\hline $\begin{array}{l}\text { Total cholesterol } \\
\text { (>5.2 mmol) }\end{array}$ & $5.20+1.31$ & $4.28+0.88$ & 0.0076 \\
\hline $\begin{array}{l}\text { Triglycerides } \\
\text { (>1.7 mmol) }\end{array}$ & $2.03+1.43$ & $1.26+0.76$ & 0.0271 \\
\hline $\begin{array}{l}\text { LDL } \\
(>3.4)\end{array}$ & $3.06+0.73$ & $2.60+0.56$ & 0.0248 \\
\hline $\begin{array}{l}\text { HDL } \\
\text { (Male < } 1 \mathrm{mmol} ; \\
\text { Female < } 1.5 \mathrm{mmol} \text { ) }\end{array}$ & $1.12+0.29$ & $1.20+0.24$ & 0.2736 \\
\hline
\end{tabular}

The triglycerides levels were higher among patients with neuropsychiatric manifestations compared to those without $1.96 \pm 1.4 \mathrm{mmol} / \mathrm{l}$ vs $1.43 \pm 0.92$ with a significant statistical difference of $p=0.019$; total cholesterol was higher among neuropsychiatric patients $4.88 \pm 1.4$ vs $4.63 \pm 1.02$ with no significant statistical difference of $p=0.512$. Table 5 shows the relationship between lipid profile and neuropsychiatric manifestations. 
TABLE 5: The Relationship Between Neuropsychiatric Manifestations and Dyslipidemia.

Total cholesterol
(>5.2 mmol)
Triglycerides
(>1.7 mmol)
LDL
(>3.4)
HDL
(Male <1 mmol;
Female <1.5 mmol)

\begin{tabular}{|c|}
\hline Neuropsychiatry \\
\hline $4.88+1.4$ \\
\hline $1.96+1.4$ \\
\hline $2.98+0.74$ \\
\hline $1.206+0.27$
\end{tabular}

\begin{tabular}{|c|}
\hline Others \\
\hline $4.63+1.02$ \\
\hline $1.43+0.92$ \\
\hline $2.74+0.63$ \\
\hline $1.07+0.23$ \\
\hline
\end{tabular}

$p$ value
0.5121
0.0195
0.2713
0.0995

The total cholesterol level was $4.65 \pm 0.70 \mathrm{mmol} / \mathrm{l}$ in patients with low complement level, and $4.71 \pm 1.26$ in patients with normal complements with no significant statistical difference of $p=0.885$; triglycerides were $1.46 \pm 1.09$ in patients with low complement level vs $1.65 \pm 1.17$ in patients with normal complement level with no significant statistical difference of $p=0.652$. Table 6 illustrates the relationship between the complement level and lipid profile.

TABLE 6: The Relationship Between Dyslipidemia and Complements Level.

\begin{tabular}{|l|c|c|c|}
\hline & $\begin{array}{c}\text { Complement Cascade } \\
\text { (Normal) }\end{array}$ & $\begin{array}{c}\text { Complement } \\
\text { Cascade (Low) }\end{array}$ & $p$ value \\
\hline $\begin{array}{l}\text { Total cholesterol } \\
(>\mathbf{5 . 2} \text { mmol) }\end{array}$ & $4.71+1.26$ & $4.65+0.70$ & 0.8851 \\
\hline $\begin{array}{l}\text { Triglycerides } \\
(>\mathbf{1 . 7} \mathbf{~ m m o l )}\end{array}$ & $1.65+1.17$ & $1.46+1.09$ & 0.6520 \\
\hline $\begin{array}{l}\text { LDL } \\
\text { (>3.4) }\end{array}$ & $2.85+0.69$ & $2.70+0.59$ & 0.5677 \\
\hline $\begin{array}{l}\text { HDL } \\
\text { (Male <1 mmol; } \\
\text { Female <1.5 mmol) }\end{array}$ & $1.25+0.26$ & $1.29+0.24$ & 0.0873 \\
\hline
\end{tabular}

The relationship between the serum albumin and lipid profile are shown in Table 7 in which the total cholesterol was $4.86 \pm 1.38 \mathrm{mmol} / \mathrm{l}$ in patients with low serum albumin vs $4.48 \pm 0.46 \mathrm{mmol} / \mathrm{l}$ in patients with normal serum albumin with no statistically significant difference of $p=0.337$; TG was $1.26 \pm 0.59 \mathrm{mmol} / \mathrm{l}$ vs $1.87 \pm 1.30$ in patients with low and normal serum albumin, respectively, with $p=0.114$; LDL was $2.91 \pm 0.71 \mathrm{mmol} / \mathrm{l}$ among patients with low albumin vs $2.78 \pm 0.48$ in normal serum albumin patients with $p=0.583$; while HDL level was $1.14 \pm 0.27 \mathrm{mmol} / \mathrm{l}$ and $1.14 \pm 0.23$ among patients with low and normal serum albumin, respectively, with $p=0.933$. 
TABLE 7: The Relationship Between Dyslipidemia and Serum Albumin.

\begin{tabular}{|c|c|c|c|}
\hline & Albumin $(<35)$ & Albumin (>35) & $p$ value \\
\hline $\begin{array}{l}\text { Total cholesterol } \\
\text { (>5.2 mmol) }\end{array}$ & $4.86+1.38$ & $4.48+0.46$ & 0.3375 \\
\hline $\begin{array}{l}\text { Triglycerides } \\
\text { (>1.7 mmol) }\end{array}$ & $1.26+0.59$ & $1.87+1.30$ & 0.1141 \\
\hline $\begin{array}{l}\mathrm{LDL} \\
(>3.4)\end{array}$ & $2.91+0.71$ & $2.78+0.48$ & 0.5835 \\
\hline $\begin{array}{l}\text { HDL } \\
\text { (Male < } 1 \text { mmol; } \\
\text { Female }<1.5 \mathrm{mmol} \text { ) }\end{array}$ & $1.14+0.27$ & $1.14+0.23$ & 0.9339 \\
\hline
\end{tabular}

\section{Discussion}

Advances in immunosuppressive therapy and supportive care have improved the survival and short-term clinical outcomes of SLE patients, with a substantial improvement in the cardiovascular morbidity and mortality, there is an increasing awareness of dyslipidemia as a major vascular risk among these patients [11].

The present data showed high total cholesterol in 17.8\%, high LDL in 15.1\%, high triglycerides in $27.3 \%$, and low HDL in $52.1 \%$ of SLE patients, hypercholesterolemia was higher than in an epidemiological study conducted among Saudi patients [12] and hypercholesterolemia was found in $8.5 \%$. A study published in Jakarta found high total cholesterol, high LDL, high triglycerides, and low HDL in $43 \%, 26.4 \%, 44.2 \%$, and $26 \%$ of SLE patients, respectively [13]. The difference in the percentages of the lipid profile can be attributed to genetic and dietary factors and the level of exercise in the two studies.

Formiga et al. [14] reported that 55\% of young premenopausal SLE women with preserved renal function had dyslipoproteinemia, similar to the current study in which $52.1 \%$ of SLE patients had dyslipidemia; another observational study conducted among children with SLE [15] reported dyslipidemia in $63 \%$ of the subjects in accordance with the current data.

In the present study, patients with lupus nephritis had higher total cholesterol, triglycerides, low-density lipoprotein, and lower high-density lipoprotein than those without lupus nephritis similar to Chong et al.'s [8] who reported higher cholesterol and triglycerides and lower HDL in lupus nephritis patients compared to control subjects.

In the current research, a positive correlation was evident between dyslipidemias (high total cholesterol, high TG, high LDL, and low HDL) and proteinuria similar to Formiga et al.'s [14] and Kashef et al.'s [16] studies, who found a positive correlation between dyslipidemias and proteinuria. Chong et al. [8] reported no correlation between 
proteinuria and dyslipidemia in contradiction to the present findings, a plausible explanation is the lower level of proteinuria in Chong et al.'s study.

In the current study the total serum cholesterol in SLE patients with lupus nephropathy was $5.4 \pm 1.4 \mathrm{mmol} / \mathrm{l}$ and was positively correlated with proteinuria and lupus nephritis; similarly, Tisseverasinghe et al. found that the serum cholesterol exceeds $5.2 \mathrm{mmol} / \mathrm{l}$ in SLE patients and was associated with mortality and adverse renal outcomes [17].

Previous literature concluded that hyperlipidemia will enhance renal immune complex-mediated complement activation and development of nephritis, in the current study, hyperlipidemia was positively correlated with proteinuria and lupus nephritis confirming the aforementioned observation [18]. In the present study, a correlation was found between hypocomplementemia and dyslipidemia that can be explained by the small size of our study.

In the present study, low-density lipoprotein was high in $14.8 \%$ and was in positive correlation with proteinuria and SLE nephropathy, in accordance with Olusi and George who concluded a prevalence of atherogenic LDL in 52\% of SLE patients [19].

Limitations: The study limitation was the small size of the study group, also we could not control for the therapy taken for SLE treatment like hydroxychloroquine which can decrease the lipids through various mechanisms.

\section{Conclusion}

Dyslipidemia was found to be higher among patients with SLE compared to the Saudi general population and was positively correlated with SLE nephropathy and proteinuria. Aggressive treatment of dyslipidemia could decrease nephropathy and overall cardiovascular risk.

\section{Conflict of Interest}

The authors declare no conflict of interest.

Disclaimer: The views expressed in the submitted article are author's own and not an official position of the institution or funder.

\section{Authors Contribution}

- Concept and design: Dr. Hyder Mirghani

- Data collection: Dr. Hyder Mirghani, Dr. Osama Salih 
- Data analysis: Dr. Hyder Mirghani

- Manuscript drafting and critical revision for important intellectual content: Dr. Hyder Mirghani, Dr. Osama Salih, Abdullah Abdul Khalig Alyoussef, Palanisamy Amirthalingam

- All authors approved the final version for publication and are accountable for the accuracy and integrity of all aspects of the work.

\section{References}

[1] Angélica Sinicato N, Aparecida da Silva Cardoso P, Appenzeller S (2013). Risk factors in cardiovascular disease in systemic lupus erythematosus. Current Cardiology Reviews. 9(1): 15-19. DOI:10.2174/157340313805076304

[2] Hak AE, Karlson EW, Feskanich D et al. (2009). Systemic lupus erythematosus and the risk of cardiovascular disease: results from the nurses' health study. Arthritis \& Rheumatology. 61(10): 1396-1402.

[3] Schoenfeld SR, Kasturi S, Costenbader KH (2013). The epidemiology of atherosclerotic cardiovascular disease among patients with SLE: a systematic review. Seminars in Arthritis and Rheumatism. 43(1): 77-95.

[4] Zeller CB, Appenzeller S (2008). Cardiovascular disease in systemic lupus erythematosus: the role of traditional and lupus related risk factors. Current Cardiology Reviews. 4(2): 116-122.

[5] Willerson JT, Ridker PM (2004). Inflammation as a cardiovascular risk factor. Circulation. 109(21): 2-10.

[6] Abou-Raya A, Abou-Raya S (2006). Inflammation: a pivotal link between autoimmune diseases and atherosclerosis. Autoimmunity Reviews. 5(5): 331-337.

[7] Machado D, Sarni RO, Abad TT et al. (2017). Lipid profile among girls with systemic lupus erythematosus. Rheumatology International. 37(1): 43-48.

[8] Chong YB, Yap DY, Tang CS et al. (2011). Dyslipidaemia in patients with lupus nephritis. Nephrology. 16(5): 511-517.

[9] Hochberg MC (1997). Updating the American College of Rheumatology revised criteria for the classification of systemic lupus erythematosus. Arthritis \& Rheumatology. 40(9): 1725.

[10] Siripaitoon B, Osiri M, Vongthavaravat V et al. (2004). The prevalence of dyslipoproteinemia in Thai patients with systemic lupus erythematosus. Lupus. 13(12): 961-968. 
[11] Chan TM (2006). Determinants of patient survival in systemic lupus erythematosus focusing on lupus nephritis. Ethnicity \& Disease. 16(2): S2-S66.

[12] Basulaiman M, El Bcheraoui C, Tuffaha M et al. (2014). Hypercholesterolemia and its associated risk factors - Kingdom of Saudi Arabia, 2013. Annals of Epidemiology. 24(11): 801-808. DOI: 10.1016/j.annepidem.2014.08.001

[13] Wijaya LK, Kasjmir Yl, Sukmana $\mathrm{N}$ et al. (2005). The proportion of dyslipidemia in systemic lupus erythematosus patient and distribution of correlated factors. Acta Medica Indonesiana. 37(3): 132-144.

[14] Formiga F, Meco JF, Pinto X et al. (2001). Lipid and lipoprotein levels in premenopausal systemic lupus erythematosus patients. Lupus. 10(5): 359-363.

[15] Tyrrell PN, Beyene J, Benseler SM et al. (2007). Predictors of lipid abnormalities in children with new-onset systemic lupus erythematosus. Journal of Rheumatology. 34(10): 2112-2119.

[16] Kashef S, Ghaedian MM, Rajaee A et al. (2007). Dyslipoproteinemia during the active course of systemic lupus erythematosus in association with antidouble-stranded DNA (anti-dsDNA) antibodies. Rheumatology International. 27(3): 235-241.

[17] Tisseverasinghe A, Lim S, Greenwood C et al. (2006). Association between serum total cholesterol level and renal outcome in systemic lupus erythematosus. Arthritis \& Rheumatology. 54(7): 2211-2219.

[18] Lewis MJ, Malik TH, Fossati-Jimack L et al. (2012). Distinct roles for complement in glomerulonephritis and atherosclerosis revealed in mice with a combination of lupus and hyperlipidemia. Arthritis \& Rheumatology. 64(8): 2707-2718. DOI:10.1002/ art.34451

[19] Olusi SO, George S (2011). Prevalence of LDL atherogenic phenotype in patients with systemic lupus erythematosus. Vascular Health and Risk Management. 7: 75-80. DOI:10.2147/VHRM.S17015 